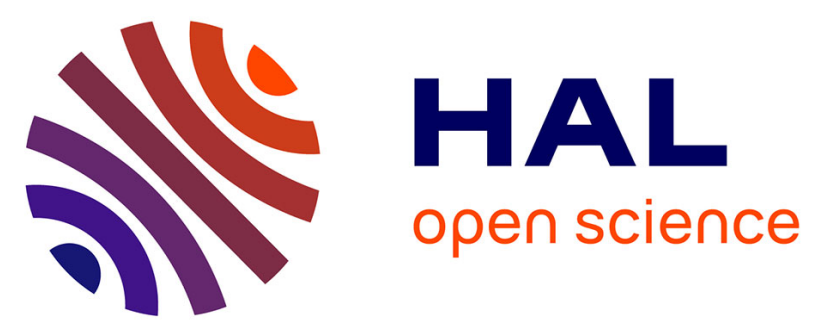

\title{
Experimental study of nanoparticle formation dynamics in HMDSO-Ar asymmetric capacitively-coupled radiofrequency plasma with application to deposition of nanocomposite layers
}

V. Garofano, L. Stafford, J. Gorka, F. Gaboriau, Bernard Despax, J. Boulon, C. Joblin, K. Demyk, Kremena Makasheva

\section{To cite this version:}

V. Garofano, L. Stafford, J. Gorka, F. Gaboriau, Bernard Despax, et al.. Experimental study of nanoparticle formation dynamics in HMDSO-Ar asymmetric capacitively-coupled radiofrequency plasma with application to deposition of nanocomposite layers. 2016 IEEE Nanotechnology Materials and Devices Conference (NMDC), Oct 2016, Toulouse, France. pp.1-2, 10.1109/NMDC.2016.7777173 . hal-02324461

\section{HAL Id: hal-02324461 \\ https://hal.science/hal-02324461}

Submitted on 1 Nov 2019

HAL is a multi-disciplinary open access archive for the deposit and dissemination of scientific research documents, whether they are published or not. The documents may come from teaching and research institutions in France or abroad, or from public or private research centers.
L'archive ouverte pluridisciplinaire HAL, est destinée au dépôt et à la diffusion de documents scientifiques de niveau recherche, publiés ou non, émanant des établissements d'enseignement et de recherche français ou étrangers, des laboratoires publics ou privés. 


\title{
Experimental study of nanoparticle formation dynamics in HMDSO-Ar asymmetric capacitively-coupled radiofrequency plasma with application to deposition of nanocomposite layers*
}

\author{
V. Garofano, ${ }^{1,2}$ L. Stafford, ${ }^{2}$ J. Gorka, ${ }^{1}$ F. Gaboriau, ${ }^{1}$ B. Despax, ${ }^{1}$ J. Boulon, ${ }^{3}$ \\ C. Joblin, ${ }^{3}$ K. Demyk, ${ }^{3}$ and K. Makasheva, ${ }^{1}$ Member, IEEE
}

\begin{abstract}
Rational engineering of nanocomposite thin layers, deposited in reactive plasmas, requires knowledge on the plasma behaviour in order to design the structural and electrical properties of the deposits. It opens the way for transition from material level of development to system level of applications. This work presents experimental study of nanoparticle formation dynamics in the plasma gas phase, along with the plasma parameters, linked to the composition of the synthesized nanoparticles before their incorporation in plasma deposits. It is found that by controlling the plasma electron temperature and density one can finely tune the nanoparticle composition as a function of reactive gas mixture.
\end{abstract}

\section{INTRODUCTION}

For many years dust formation in reactive plasmas was undesired phenomenon giving rise to pollution of deposited thin films [1]. Currently, study of formation of nanoparticles in plasmas is rather oriented to drawing benefits of this phenomenon targeting a controlled deposition of nanocomposite thin films through incorporation of the plasma dust into the growing layer [2]. Better understanding, and the following detailed description, of such heterogeneous systems remains an intensive field of research, as they represent interesting building blocks for deposition of multifunctional thin films, and largely contribute to the development of nanotechnology.

Hexamethyldisiloxane (HMDSO, $\left.\mathrm{Si}_{2} \mathrm{O}\left(\mathrm{CH}_{3}\right)_{6}\right)$ is one of the most commonly used organosilicon monomers for plasma depositions [3]. While HMDSO thin film deposition has been extensively studied, plasma behaviour and the plasma-phase reactions of HMDSO remain in a niche, especially in the context of nanoparticle formation in the gas discharge. The use of HMDSO and other organosilicon precursors for microelectronics and deposits is wide spread due to easiness of preparing good quality coatings at low temperature and much better safety in handling of the precursors. Also other applications such as optics, barrier films for food packaging,

* Research supported by the program of the Fondation de Coopération Scientifique "Sciences et Technologies pour l'Aéronautique et 1'Espace", RTRA-STAE in France, project $3 \mathrm{PC}$ keys under Contract $\mathrm{N}^{\circ} \mathrm{RTRA}-$ STAE/2014/P/3PCKEYS/01.

V. Garofano, J. Gorka, F. Gaboriau, B. Despax, and K. Makasheva are with LAPLACE laboratory, Université de Toulouse; CNRS, UPS, INPT; 118 route de Narbonne, F-31062 Toulouse, France (e-mail: kremena.makasheva@laplace.univ-tlse.fr).

V. Garofano and L. Stafford are with Département de physique, Université de Montréal, Montréal, Québec H3C 3J7, Canada (e-mail: luc.stafford@umontreal.ca).

J. Boulon, K. Demyk and C. Joblin are with IRAP-OMP, Université de Toulouse; CNRS, UPS; 9 avenue du Colonel Roche, F-31028 Toulouse, France (e-mail: christine.joblin@irap.omp.eu). interlayer dielectrics and corrosion protection layers can benefit to large extend from plasma deposition processes but requires a deep knowledge on how the precursor molecule decomposes under plasma conditions.

To go further in the development of plasma processes for layer deposition we investigate an original method of nanoparticle formation based on pulsed injection of HMDSO and gradually change the reactive gas mixture by adding oxygen $\left(\mathrm{O}_{2}\right)$ to it. Thus the aim is to reproduce the transition between carbon-rich and oxide particles by investigating a range of plasma operating conditions including $\mathrm{RF}$ power, HMDSO pulsed injection, and oxygen concentration. In addition to controlled nanocomposite layer deposition this approach adds value to elaboration of laboratory cosmic dust analogues [4]. The carbon to oxygen ratio $(\mathrm{C} / \mathrm{O})$ in the atmospheres of evolved stars is known to determine the type of cosmic dust that is formed (carbon-rich if $\mathrm{C} / \mathrm{O}>1$ or silicates and oxides if $\mathrm{C} / \mathrm{O}<1$ ).

\section{EXPERIMENTAL PART}

To accomplish controlled deposition of nanocomposite layers we have used an axially-asymmetric radiofrequency (RF, $13.56 \mathrm{MHz}$ ) capacitively-coupled discharge maintained in HMDSO-Ar at low gas pressure (50-60 Pa, depending on the gas mixture) with power of 5-20 W [5]. The HMDSO was injected by pulses with period $T=t_{\text {on }}+t_{\text {off }}$. The dust formation is observed for $t_{o n}>2 \mathrm{~s}$ over $5 \mathrm{~s}$ period of the pulse. The maximum HMDSO flow which corresponds to continuous injection was $0.4 \mathrm{sccm}$. Oxygen flow was varied in the range $0.075-0.175 \mathrm{sccm}$. The RF-driven top electrode (smaller, $10 \mathrm{~cm}$ in diameter, made of silver) was placed in front of a bottom electrode (larger, $12 \mathrm{~cm}$ in diameter) with a gap distance equals to $3.5 \mathrm{~cm}$. The bottom electrode and the walls were grounded. The axially-asymmetric design of that RF discharge produces axially-asymmetric plasma inducing a self-bias voltage $\left(\mathrm{V}_{\mathrm{dc}}\right)$ on the powered electrode. The selfbias voltage scales up, in modulus, with the injected power, at a constant pressure and is at the origin of the acceleration of argon ions towards the silver target to achieve bombardment. The most appropriate way to follow the plasma behavior in order to relate it to the plasma deposits is through optical emission spectroscopy of the plasma glow emission as the line intensities increase with either the electron energy or the electron density. Trace Rare Gases Optical Emission Spectroscopy (TRG-OES) was used to analyze the very-low-frequency cyclic evolution of the electron energy and density caused by repetitive formation and loss of nanoparticles. Evolution in the dust composition was followed by infrared spectroscopy (FTIR) in the $4000-$ 
$250 \mathrm{~cm}^{-1}$ range $(2.5-40 \mu \mathrm{m})$. The obtained spectra on the nanoparticles formed in the plasma gas phase were compared to spectra recorded on thin layers deposited on Si-substrates.

\section{RESULTS AND DISCUSSION}

Results obtained by TRG-OES [6] give an electron temperature that characterizes the high energy part of the electron energy distribution function (EEDF) in the plasma. Its mean value is around $1 \mathrm{eV}$ and it follows the nanoparticle formation and disappearance cycle (Fig. 1). By elaborating Boltzmann diagrams for 4 emission levels close in energy, we were able to obtain a second electron temperature, characterizing the low energy part of the EEDF (not shown). This temperature also fluctuates with the dust cloud in similar way, but around a mean value of $0.18 \mathrm{eV}$. The fact that both temperature values are apart signifies that the EEDF is not characterized by a single Maxwellian distribution. Evolution of the high-energy electron density was obtained using the Arrhenius equation. Its behavior is in anti-phase with the emission line intensities and temperature measurements. These results confirm the fact that nanoparticles attach an important quantity of negative charges, which induces an elevation of the mean electron energy in order to maintain the plasma.

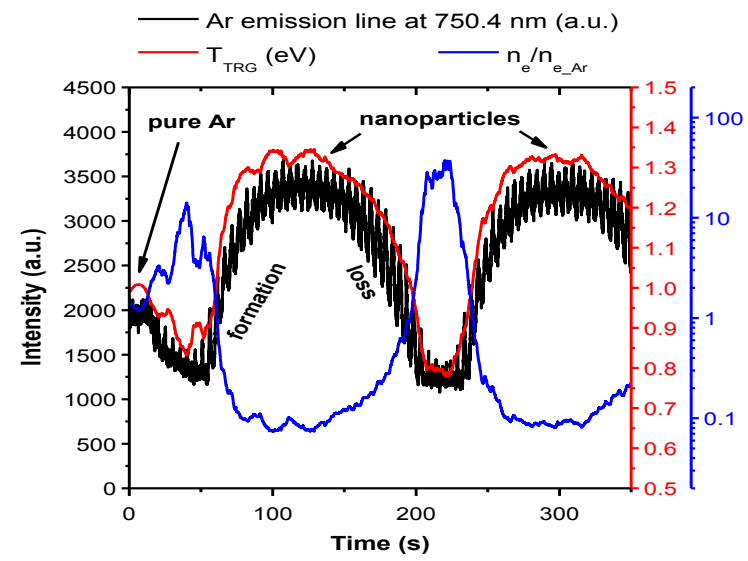

Fig. 1. Very-low-frequency cyclic evolution of the argon line at $750.4 \mathrm{~nm}$ (black curve), electron temperature of high-energy electrons $T_{T R G}$ (red curve) and high-energy electron density normalized to the electron density in pure Ar plasma (blue curve). The power was fixed to $30 \mathrm{~W}$, with HMDSO injection time $t_{o n}=3.5 \mathrm{~s}$ over a period of $5 \mathrm{~s}$.

The nanoparticles were collected at fixed conditions over long time ( $3 \mathrm{hrs}$ ) to ensure enough material to be produced for the evaluation of their structural properties by FTIR and SEM analyses (Fig. 2). FTIR analysis of nanoparticles formed in HMDSO-Ar plasma confirmed the presence of characteristic Si-O-Si bands as well as $-\mathrm{CH}_{3}$ bands, essentially the same as those found in HMDSO plasma deposits [3]. SEM revealed that the collected powders are composed of agglomeration of relatively small primary particles. When $\mathrm{O}_{2}$ is added to the gas mixture, FTIR analysis (Fig. 2(b)) revealed two prominent features of the studied materials, i.e. very broad $\mathrm{Si}-\mathrm{O}-\mathrm{Si}$ bands and decreased intensity of $-\mathrm{CH}_{3}$ band as more oxygen is introduced into the plasma admixture. The first feature suggests polymeric rather than amorphous nature of the material. The decrease in the intensity of $-\mathrm{CH}_{3}$ bands is a clear indication of progressive elimination of carbon from the nanoparticles, as seen in Fig. 2(b). Even though the carbon amount in the particles decreases, the formed nanoparticles are still considered to be C-rich. To attain oxide nanoparticles, the $\mathrm{O}_{2}$ flow should substantially be increased and, at the same time, the nanoparticle formation phenomenon should be preserved.
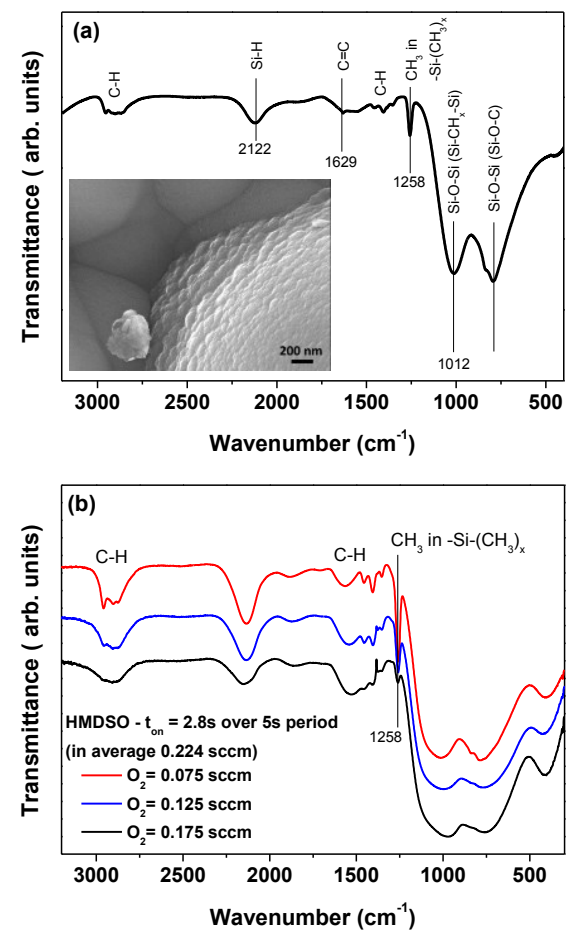

Fig. 2. Recorded FTIR spectra on collected nanoparticles: (a) in HMDSO-Ar discharge, an image of the collected nanoparticles is show in inset; (b) evolution of the FTIR spectra with gradual introduction of $\mathrm{O}_{2}$ into the HMDSO-Ar discharge.

\section{CONCLUSION}

Cyclic formation of nanoparticles in plasmas and the evolution of plasma parameters are closely interrelated. The composition of synthesized nanoparticles can finely be tuned by progressive changes in the reactive gas mixture.

\section{REFERENCES}

[1] A. Bouchoule and L. Boufendi, "Particulate formation and dusty plasma behaviour in argon-silane RF discharge," Plasma Sources Sci. Technol., vol. 2, pp. 204-213, 1993.

[2] U. Kortshagen, "Nonthermal plasma synthesis of semiconductor nanocrystals," J. Phys. D: Appl. Phys., vol. 42, p. 113001, 2009.

[3] B. Despax and P. Raynaud, "Deposition of "Polysiloxane" Thin Films Containing Silver Particles by an RF Asymmetrical Discharge," Plasma Process. Polym., vol. 4, pp. 127-134, 2007.

[4] T. Henning, "Laboratory Astrophysics of Cosmic Dust Analogues," Lect. Notes Phys., vol. 815, pp.313-329, 2010.

[5] B. Despax, K. Makasheva, and H. Caquineau, "Cyclic powder formation during pulsed injection of hexamethyldisiloxane in an axially asymmetric radiofrequency argon discharge," J. Appl. Phys., vol. 112, p. 093302, 2012.

[6] V. Garofano, L. Stafford, B. Despax, R. Clergeraux, and K. Makasheva, "Cyclic evolution of the electron temperature and density in dusty low-pressure RF plasmas with pulsed injection of hexamethyldisiloxane," Appl. Phys. Lett., vol. 107, p. 183104, 2015. 